\title{
Key Drivers of Customer Loyalty to Web 2.0 Accommodation Services: An Abstract
}

\author{
Enrique Bigné, Carla Ruiz, Jose Tronch, and Silvia Sanz
}

\begin{abstract}
Online travel communities are regarded as a key communication channel for web-based marketing in the travel industry (Bilgihan et al. 2016; Filieri 2015). The aim of this paper is to gain insight on key drivers of customer loyalty to websites selling accommodation services in online travel communities. We go beyond satisfaction, taking into account emotions and social influences. This paper intends to make three contributions. Firstly, it develops a conceptual model of the relationships between emotion factors and their direct (satisfaction) and indirect (trust, attitude and loyalty) outcome variables. Secondly, although the linear relationship between satisfaction, trust and loyalty seems almost intuitive, we propose interaction with other variables (e.g. attitudes, emotions) in Web 2.0 environments can affect these relationships. Thirdly, this research suggests that social influence perspective can integrate with the relational framework, assessing the normative and voluntary role of others in consumer loyalty in 2.0 environments. We test our conceptual model using a sample of 385 Spanish active users of websites selling accommodation services, who had already used online travel communities. Data analysis shows that positive and negative emotions significantly influence loyalty formation with a pivotal effect on satisfaction, trust and attitude. Emotion factors were found to have a direct influence on consumer satisfaction with accommodation services booked through online travel communities and an indirect effect on loyalty. This research also shows that both normative and voluntary influences have a significant effect on loyalty formation. Therefore, our results indicate a greater influence of the process of identification and interactions with other community members rather than the compliance process. Managerial implications and future research lines are provided.
\end{abstract}

References Available Upon Request

Authors acknowledge support by Grant ECO2014-53837R.

E. Bigné $(\bowtie) \bullet$ C. Ruiz $\bullet$ J. Tronch $\bullet$ S. Sanz

University of Valencia, Valencia, Spain

e-mail: Enrique.Bigne@uv.es; carla.ruiz@uv.es; jose.tronch@uv.es; silvia.sanz@uv.es

(C) Academy of Marketing Science 2017

P. Rossi (ed.), Marketing at the Confluence between Entertainment and Analytics, Developments in Marketing Science: Proceedings of the Academy of Marketing Science, DOI 10.1007/978-3-319-47331-4_277 